\section{Controversy continues}

SIR-We have followed with interest the debate resulting from the publication of Benveniste's paper ${ }^{1}$ and the controversy over the reproducibility of results.

Biological systems are notoriously unpredictable because of our limited knowledge of their interactions, and repeated experiments are often required before a general trend can be discerned. It is surely unscientific to dismiss five years work on the basis of results obtained in a mere five days. Might not Maddox et al. ${ }^{2}$ themselves be falling into the trap of insufficient data to eliminate sampling errors? It is, after all, much more difficult to prove a negative finding than a positive one. A similar criticism applies to the more recent reports since published ${ }^{3,4}$ which may also fall into the trap described by Gracely where observer expectation influences the results 5 .

The idea that homoeopathic principles "strike at the very basis of chemistry" and require that "the Law of Mass Action or Avogadro's number" be thrown away is illogical. It is often forgotten that homoeopathic remedies are frequently prescribed in material doses and that although the high dilutions, or high potencies, which are a later refinement, are of great clinical value ${ }^{6}$, they are not essential to the practice of homoeopathy, nor are they its basis.

Biology often presents us with apparent paradoxes which, with greater knowledge, are resolved. Not many years ago, the world of immunology was split by the controversy as to whether immunity was humoral or cell mediated. In the event, it turned out that both factors were important in the development of the immune reaction and the controversy ceased to exist. Perhaps sophisticated developments in quantum physics will similarly resolve the controversy over the nature of homoeopathic remedies.

Robin G. Gibson

SHeIla L.M. Gibson Glasgow Homoeopathic Hospital,

1000 Great Western Road,

Glasgow G12 ONR, UK.

1. Davenas E. et al. Nature 333, 816 (1988)

2. Maddox J. et al. Nature 334, 287 (1988).

3. Seagrave J C. Nature 334, 559 (1988).

.

. Bonini, S. et al. Nare 334, 559 (1988)

$43(1985)$

6. Gibson S.L.M. \& Gibson R.G. Homoeopathy for Everyone, (Penguin, London, 1987).

SIR-The scientific world will reject the findings of Jacques Benveniste and for good reasons, although the argument for a biological effect at high dilution is unlikely to die. More interesting than the debate over the quality of these particular experiments are the reasons why the physical demonstration of such phenomena should have such an allure. James Randi, prob- ably unconsciously, puts his finger on the answer when he describes the reaction of such claims as akin to that ensuing if he were to say, "I keep a unicorn in my back yard". The point, however, is not our incredulity at such a statement but the fact that we might wish it were true, and for reasons that that have nothing to do with the rational mind but reflect a profound human need.

These 'high-dilution' experiments and much of homoeopathy evoke a similar response with their notions of alchemy. Their quasi-scientific explanations conceal an effect which relies upon engendering a sense of the wondrous and even the mystical. We wish to 'believe the unbelievable', to be over-awed and uncomprehending. Of course, the myths and legends served this purpose, and until the recent past the birth/death cycle of nature amply fulfilled this need. But science unwittingly destroys this awe-inspiring element. The explanations of the Sun rise, eclipses and procreation no longer invoke the pantheon of the gods, but can be reduced to mathematical formulae and test-tube demonstrations.

We might well pause to reflect upon the consequences of this loss and the atrophying of our sense of wonder. As Ecclesiastes says: "In much wisdom is much grief: and he that increaseth knowledge increaseth sorrow". (1:18)

Morris Doublet-STEWART Christine Doublet-Stewart

Hôpital Edouart Herriot,

Place d'Arsonval,

69437 Lyon Cedex 03,

France

SIR-Following the Benveniste saga, perhaps the time has come for the creation of an independent body to scrutinize laboratory work during the early stages of research.

One possibility would be the borrowing of methods employed by agencies such as the Inland Revenue, namely the tactic of the hit squad. A roving gang of suitably qualified scrutineers would descend unannounced upon unsuspecting laboratories, ruthlessly checking routines for the inclusion of relevant sampling and statistical errors. Spurious research would thereby be eliminated at an early date, benefiting researcher and reader alike, while more controversial research would be subject to the rigours of investigation normally reserved only for those working outside the scientific paradigm.

In fact, if the Inland Revenue inspectors could be persuaded to undertake such a task, a double benefit could be had in the discovery of any financial irregularities within the chosen laboratories.

The creation of such a system would provide the suitable climate of moral fear and financial accountability under which basic science is expected to operate.

Institute of Laryngology and G.J. Neville Otology,

330/332 Gray's Inn Road, London WC1X $8 E E, U K$

SIR-Setting aside for a moment the issue of the scientific reliability of the Benveniste work, I wish to add my voice to those who have been dismayed by the approach to this case taken by Nature. The elements of farce, witch hunt and arrogance noted in the press should have been readily appreciated in advance - I would hope not intentionally - as a way of teaching anyone a lesson. This affair does not serve the cause of science, and most particularly not the cause of science's long-suffering public image.

Regrettably, it is typical of the lack of self-reflection of 'establishment' science, and reactionary response to much that is on the border of 'new science'. Galileo, Kerkule, Tesla and Einstein all survived, Reich died in prison labelled a fraud by the US Food and Drug Administration. How much of what is published as 'science' in modern journals would survive exhaustive self-delusion tests? How much is ever repeated, especially when large expenses are involved?

Political Ecology Research Group

Peter TAYlor

Limited,

34 Cowley Road,

Oxford OX4 1HZ, UK

\section{World of guesses}

SIR-I am surprised at your continuance of the "creationism and science" correspondence. The writers of such letters on both sides of the debate have singularly failed to realize that:

(1) what we call knowledge (or science) is only a variably tested guess at what exists outside the reference point for certainty, which is consciousness of oneself;

(2) the words proof, truth and objectivity do not apply in the world of guesses;

(3) we work as 'scientists' to increase the confidence we can place in those guesses that describe and/or explain that which seems to exist beyond and within the self; (4) explanations that involve concepts of 'gods' or other 'supernaturals' are guesses as other guesses are; the extent to which they are useful guesses is determined by the degree to which they can be reliably applied to arrive at knowledge of the nonself world and thereby provide the guidelines for building systems of morals.

R. E. SPIER

Department of Microbiology,

University of Surrey,

Guildford,

Surrey GU2 $5 X H, U K$ 